\title{
Apontamentos PARA EPISTEMOLOGia F MÉtodos NA PESQUiSA EM COMUNICAÇÃo NO BRASIL
}

\author{
Cicilia M. Krohling Peruzzo
}

\begin{abstract}
Resumo
Este texto tece alguns aspectos da pesquisa em Comunicação partindo da filosofia do conhecimento como base para se entender a ciência. Tem como objetivos discutir a questão da pesquisa científica na perspectiva epistemológica, atentar para a importância da metodologia científica em suas dimensões metódicas e técnicas, além de refletir sobre alguns aspectos da pesquisa realizada na América Latina e mais especificamente o Brasil. Trata-se de uma abordagem baseada numa revisão teórica não exaustiva e não sistemática. Considera-se a existência de diversidade temática e metodológica, além da aparente tendência da pesquisa em enfocar a novidade, principalmente de elementos relacionados à tecnologia, como objeto de estudo. Também se comenta sobre a premência do fortalecimento das pesquisas em Comunicação, tanto as teóricas quanto as empíricas, e do avanço necessário no desenho e na descrição dos métodos e técnicas de pesquisa quando da apresentação de resultados e análises.
\end{abstract}

\section{Palavras-chave}

Empirismo; epistemologia; metodologia; pesquisa em Comunicação

\begin{abstract}
This text weaves some aspects of research in Communication starting from the philosophy of knowledge as a basis for understanding science. It aims to discuss the issue of scientific research in the epistemological perspective, to consider the importance of scientific methodology in its methodical and technical dimensions, as well as to reflect on aspects of the research carried out in Latin America and more specifically in Brazil. It is a theoretical approach based on a non-systematic and non-exhaustive literature review. The existence of thematic and methodological diversity is examined, as well as the apparent tendency of the research to focus on the novelty, mainly in regards to elements related to technology, as object of study. The urgency of strengthening research in Communication is also considered, both theoretical and empirical, and the necessary advance in the design and description of research methods and techniques when presenting results and analyzes.
\end{abstract}

KEYwORDS

empiricism; epistemology; methodology; research in Communication

\section{INTRODUÇÃO}

Este texto tece alguns aspectos da pesquisa em Comunicação partindo da filosofia do conhecimento como base para se entender a ciência, no intuito de provocar reflexões e debates, porém sem a pretensão de abordar todos os componentes que lhe dizem respeito. Tem como objetivos discutir a pesquisa científica em Comunicação na perspectiva 
epistemológica, atentar para a importância da metodologia científica em suas dimensões metódicas e técnicas, além de refletir sobre aspectos das tendências e qualidade da pesquisa realizada na América Latina e mais especificamente no Brasil. Mais do que respostas, pretendemos provocar debates e deixar perguntas para futuras reflexões.

Inicialmente, parece-nos premente reconhecer a existência de diversidade temática e metodológica abrigadas sob o manto da pesquisa em Comunicação. Os estudos enfocam desde temas relacionados aos meios de comunicação, melhor dizendo, de meios de informação, tais como rádio, jornal, televisão e cinema, chegam aos ambientes comunicacionais na internet com pesquisas sobre cibercultura, dispositivos tecnológicos, interatividade, mídias e redes sociais online, mas englobam também a comunicação organizacional e as relações públicas, a publicidade, a comunicação pública, a comunicação interpessoal e grupal, a comunicação popular, comunitária e alternativa, entre outros meios e formas comunicativas. Com base numa revisão de literatura assistemática e não-exaustiva da produção científica em publicações e trabalhos apresentados em congressos, bem como na pesquisa bibliográfica realizada para este artigo, podemos afirmar que as ênfases têm recaído em estudos de Jornalismo e, mais recentemente, sobre a cibercultura, a partir da emergência do fenômeno internet e a acentuada preocupação com a mediação tecnológica nos fenômenos comunicacionais e culturais. Abordagens relacionadas às identidades culturais, aos imaginários e às representações narrativas nas ou a partir das mídias, em parte sob a influência da perspectiva teórica dos estudos culturais, também se fazem presentes nos estudos de Comunicação.

Da mesma forma, observamos algumas tendências no percurso da pesquisa em Comunicação. Uma delas é o modismo, ou a eleição de abordagens modais relacionadas a fenômenos emergentes - especialmente decorrentes do desenvolvimento tecnológico, acontecimentos marcantes' ou da chegada no país de teorias já em evidência em outros países, especialmente nos Estados Unidos ou na Europa. Por exemplo, durante muito tempo a televisão despertou muito interesse como unidade de observação, tanto do ponto de vista crítico quanto para entender suas lógicas de produção jornalística e de entretenimento. Recentemente a questão das novas tecnologias, em especial a partir da internet e da constituição do ciberespaço é que atrai muitos pesquisadores, como atesta a quantidade expressiva de estudos sobre cibercultura e as configurações e usos de mídias e redes sociais online apresentados em congressos e publicados em revistas científicas e em livros, tornando-se inclusive em uma subárea da Comunicação e criando até uma associação de pesquisadores ${ }^{2}$. Outra tendência, em parte ligada à anterior, é o acentuado interesse de pesquisa em fenômenos emergentes. Antes foi a internet em si, seu surgimento e enquanto tecnologia propiciadora de um espaço de liberdade de expressão, sociabilidade etc. e, atualmente, o olhar se volta mais para as suas

\footnotetext{
' Interesse, por exemplo, em estudar o tratamento dado pela imprensa ao caso do impeachment da presidenta Dilma. Outro exemplo: Depois das grandes manifestações públicas em junho de 2013, no Brasil, por exemplo, que fizeram vir à tona de forma mais evidente o papel das mídias alternativas, apesar de existentes há décadas, se acentua o interesse em estudá-las.
}

${ }^{2}$ ABCiber - Associação Brasileira de Pesquisadores em Cibercultura. Ver: https://abciber.org.br/ 
configurações que se inovam (Big Data, algoritmos, robôs, sistemas tecnológicos inteligentes...), as alterações que provoca em padrões culturais, potencialidade dos compartilhamentos e de participação, e assim por diante. São aspectos talvez característicos de uma área de conhecimento, cujos pilares transformam-se rapidamente, além de serem marcados pela interdisciplinaridade complexa e dinâmica. Nesse contexto, híbrido e movediço do campo da Comunicação, outra tendência por nós observada ao longo dos anos é a ênfase em abordagens investigativas que apenas tangenciam a comunicação enquanto objeto central de pesquisa. É o caso de estudos que têm como eixos analíticos parâmetros tecnológicos, culturais ou processuais mais afeitos a outras áreas do conhecimento, e não conseguem enxergá-los a partir da própria comunicação ou dos processos comunicacionais envoltos nos fenômenos investigados.

Quanto às metodologias empregadas nas pesquisas em Comunicação, não é novidade que ocorra a apropriação de métodos e técnicas desenvolvidos em outras áreas do conhecimento, embora haja algum esforço em "trazê-los" ou adaptá-los às especificidades da área da Comunicação. Referimo-nos a métodos e técnicas como a hermenêutica, a pesquisa histórica, a etnografia, análise de conteúdo, análise de discurso, a observação participante, grupo de discussão, grupo focal, questionários e entrevistas. Contudo, algumas destas abordagens têm mais afinidade aos objetos da Comunicação, tais como a análise de conteúdo, análise de discurso, entrevistas abertas e o grupo focal, além do desenvolvimento de métodos e técnicas mais característicos empregados em pesquisas de audiência e de recepção, especialmente a criação de medidores eletrônicos e as observações da recepção no momento da exposição de pessoas a conteúdos da televisão, por exemplo, de telenovelas.

\section{Pesquisa CIENTífiCA: A NECESSIDADE DE UM PASSO ATRÁs}

A discussão sobre pesquisa em Comunicação traz uma questão de fundo: a ciência. Estamos produzindo ciência? O que caracteriza uma pesquisa científica? Trata-se de um debate não recente, nem simples, muito menos acabado. Ele se aloja na filosofia da ciência e na teoria do conhecimento, cujas fronteiras são de difícil visualização, e remetem à epistemologia da ciência. Como diz Blanché (citado em Santos, 1989, p. 19), a epistemologia é uma "reflexão de segundo grau sobre a ciência, uma meta ciência". Desse modo, não se emprega o termo epistemologia como sinônimo de teoria, pois se refere ao entendimento profundo do percurso da natureza da investigação científica, de suas bases epistêmicas. Piaget $\left(2011\right.$, p. 20) ${ }^{3}$, elege a epistemologia à categoria de disciplina que "se propõe a interpretar a ciência como resultado da atividade mental do homem ou, o que significa o mesmo, a explicar como o pensamento real do homem pode produzir a ciência enquanto sistema coerente de conhecimentos objetivos". Portanto, tratando-se da pesquisa em Comunicação, do ponto de vista epistemológico se investiga a Comunicação como objeto de conhecimento, tanto no nível teórico quanto dos processos epistêmicos e metódicos a partir dos quais se gera o conhecimento, e que

\footnotetext{
${ }^{3}$ Ele credita a coautoria desta frase a E. W. Beth.
} 
indicam os elementos de sua consistência e validação. Esse tem sido um empreendimento de pesquisadores em nível internacional, a exemplo de Calhoun (2012), Fuentes Navarro (2008, 2015), Galindo Cáceres (2008), Morágas Spà (2011) e Martín Serrano (2007), e inclusive no Brasil, porém, em menor escala, pois a tendência predominante se direciona no entendimento da institucionalização do campo. Segundo Lopes (2010, p. 29), há "descaso pelas questões epistemológicas nas pesquisas empíricas da Comunicação, fruto da deficiente formação em pesquisa e da herança instrumentalizada de ciência, possivelmente a mesma que identifica a Comunicação como ciência social 'aplicada' na classificação institucional".

Voltando à questão da ciência, há diferentes caminhos a partir de posições epistemológicas e de marcos conceituais para a geração do conhecimento científico. Trataremos de forma breve do empirismo, em contraponto a visões que questionam alguns de seus pressupostos, como os de considerar os seus parâmetros de pesquisa como únicos capazes de levar à ciência. Esta se aloja no positivismo, corrente epistêmica defensora da supremacia do objeto em relação ao sujeito no processo de pesquisa. Trata-se de uma concepção de ciência herdada da Física, uma ciência exata que traduziria os postulados científicos válidos para todas as áreas. Comte (citado em Triviños, 2012, p. 33), importante sistematizador do positivismo, chegou a denominar de "física social" a Sociologia, como disciplina voltada ao estudo dos fatos sociais.

Nesse patamar há a defesa de que o conhecimento científico seria gerado a partir de processos de pesquisa metodologicamente objetivos, pretensamente neutros (examinar a realidade de modo desinteressado), capazes de privilegiar o objeto sobre o sujeito, ou seja, de captar sensorialmente o conhecimento que existe no objeto sem a "contaminação" do sujeito, o/a investigador/a. Nas palavras de González (2007, p. 48),

as posições empiristas privilegiam o lado do objeto sobre o sujeito. Supõem que a realidade está fora do sujeito, e existe independentemente dele. Seu conhecimento se resume em observar, registrar e escrever, com todo detalhe e sem contaminações pessoais, as características do objeto.

Algumas das características dessa perspectiva epistêmica são as de atribuir à ciência a função de "ver para prever"; de tomar a realidade como formada de partes isoladas; de não se interessar pelas causas dos fenômenos; de rejeitar o conhecimento metafísico uma vez considerado especulativo; de acreditar que o conhecimento "verdadeiro" é aquele empiricamente verificável (Triviños, 2012, pp. 35-37), daí a valorização do experimento e de hipóteses passíveis de serem verificadas a partir de observações empíricas, pela dedução, e de métodos e técnicas derivados de cálculos matemáticos e da estatística. Essa corrente considera, como já foi citado, que somente os parâmetros desenvolvidos no âmbito epistêmico ligado ao empirismo seriam válidos e capazes de gerar conhecimento científico e, que, portanto, deveriam ser seguidos por todas as áreas do conhecimento. Advoga que a observação deve ser subordinada à observação dos fatos, como único objeto da ciência, pois a realidade contém a "verdade", e cabe ao pesquisador ${ }^{4}$ captá-la.

\footnotetext{
${ }_{4}^{4}$ Doravante se faz o uso das palavras no masculino, mas sem desconsiderar a igualdade de gênero nessas questões.
} 
Trata-se de uma posição predominante na histórica da ciência, apesar de ser ao mesmo tempo questionada em sua perspectiva universalista. Paul Feyerabend (1977), ainda no século passado, foi um dos expoentes críticos do racionalismo e da rejeição de regras metodológicas universais5. Entre outros epistemólogos, Jean Piaget (2011) e Rolando Garcia $(2002,2008)$ se destacam como críticos do empirismo enquanto concepção de ciência. Em última instância, existem diferentes correntes de pensamento, as quais se alojam em concepções epistemológicas do labor científico, diferentes entre si, porque partem de pressupostos divergentes quanto à visão de mundo e de ciência, tais como o positivismo, a fenomenologia, o estruturalismo, o enfoque sistêmico, o materialismo histórico dialético, o construtivismo e a epistemologia genética.

Sem entrar nas especificidades de cada um desses modos de conceber a ciência e de produzir o conhecimento, que, aliás, sempre indicam uma tomada de posição que antecede a pesquisa, além das bases do caminho a trilhar no processo de geração do conhecimento científico, fazemos apenas um contraponto da visão predominante baseada no empirismo com uma síntese de visões que se negam a ver a ciência nessa perspectiva, como a única válida e aplicável a todas as áreas do conhecimento. Essa visão se aloja em diferentes enfoques, mas principalmente no materialismo histórico dialético, no construtivismo e na epistemologia genética. É uma perspectiva crítica que questiona, por exemplo, a ideia de neutralidade científica que se presume existir nos estudos empiristas, uma vez fundamentados em metodologias objetivas. De fato, não existe postura neutra, mesmo nos métodos que assim creem ser, pois toda variável e tipo de abordagem implicam escolhas que advêm de concepções de mundo. Os enfoques epistemológico e teórico-metodológico partem de uma posição epistêmica, de um alinhamento com determinados interesses e visões de sociedade. Fals Borda (2013, p. 302) adverte: o valor da ciência varia "segundo os interesses objetivos das classes sociais envoltas nas formação e acumulação do conhecimento, isto é, em sua produção". Afinal a

a ciência é um produto cultural do intelecto humano, produto que responde a necessidades coletivas concretas (...) e também a objetivos determinados por classes sociais que aparecem como dominantes em certos períodos históricos. Se constrói a ciência mediante a aplicação de regras, métodos e técnicas que obedecem a um tipo de racionalidade convencionalmente aceita por uma comunidade minoritária constituída por pessoas chamadas de cientistas, que por serem humanas, ficam precisamente sujeitas a motivações, interesses, crenças e superstições, emoções e interpretações de seu desenvolvimento social específico. Por isso mesmo, não pode haver nenhum valor absoluto atribuído ao conhecimento científico. (Fals Borda, 2013, p. 302)

\footnotetext{
${ }_{5}^{5}$ No fundo há receio de que métodos e metodologia possam inibir a geração de conhecimento. Gumbrecht, H.U. (citado em Sodré, 2014, p. 288) chega a recomendar: "não acredite em nenhum 'método' ou (pior) metodologia - não porque os métodos ou as metodologias sejam intrinsicamente maus, mas porque eles impedem de pensar de modo independente e de desfrutar sua liberdade intelectual em uma dimensão de pensamento que não admite regulações rígidas".
} 
A produção do conhecimento científico se transforma em conformidade com as condições de sua produção e da própria demanda por conhecimento das sociedades em determinado momento. Quando seus parâmetros tidos como infalíveis são questionados é porque existe a busca por novas formas de pesquisa, por outro tipo de conhecimento e por novos tipos de resultados científicos capazes dar explicações diferenciadas e de entender as problemáticas postas pela vida em sociedade. Talvez seja essa a razão de Carlos R. Brandão (1999, p. 225) afirmar que a "possibilidade de transformação de uma prática científica, que durante tanto tempo ocultou o seu ser política, em uma prática que justamente por afirmar-se política na origem e no destino, reclama ser científica". Nesta frase está a afirmação da demanda de segmentos sociais por outros tipos de pesquisa, como os que possam ajudar a compreender a realidade das classes subalternizadas e também colaborar para a transformação da práxis sócio organizativa de base, sem promessa de neutralidade, mas buscando a cientificidade. Trata-se, por exemplo, da pesquisa participante, especialmente da pesquisa-ação no contexto dos movimentos sociais populares da América Latina. Porém, claro que o mencionado método não tem sua aplicabilidade limitada aos movimentos emancipatórios, pois é usado em várias áreas do conhecimento (Thiollent, 1981; 2003) e a partir das mais diferentes finalidades, tanto no mundo empresarial quanto na Educação, na Psicologia, na Informática, na Agronomia e na Comunicação.

Enfim, reivindica-se o reconhecimento da cientificidade em pesquisas que destoam dos cânones "tradicionais". Não que estes não sejam válidos e importantes, pelo contrário, mas que não podem ser tomados como únicos parâmetros para medir a cientificidade. Não é aceitável que os padrões das ciências exatas e da saúde, entre outras, sirvam de parâmetros para todas as ciências, inclusive, para as humanas e sociais. Há domínios da vida social e cultural (Minayo, 2011) que podem ser mais bem compreendidos e interpretados por meio de pesquisas qualitativas uma vez situados no universo dos significados, dos valores, das aspirações e atitudes. Em outras palavras, há ambientes e problemáticas que podem ser mais bem entendidos a partir de conceitos, métodos e técnicas não exatos, não experimentais e não quantificáveis.

$\mathrm{Na}$ verdade, na história da ciência há um processo contínuo de desenvolvimento epistemológico e de metodologias de pesquisa em desafio à compreensão dos fenômenos mais diversos desse mundo. É um percurso no qual se aperfeiçoam e se desenvolvem tanto metodologias quantitativas - dos questionários impressos aos virtuais, medidores eletrônicos para quantificar as audiências etc. -, quanto as qualitativas - da observação participante à participação observante e desta à pesquisa-ação participativa (Peruzzo, 2016), da etnografia à netnografia. Além de que permanecem sempre atuais a entrevista semiestruturada e a entrevista em profundidade, como a história oral, a história de vida, a história de família, grupo focal e grupo de discussão. São metodologias abertas e também capazes de gerar observáveis científicos e conhecimento. A ideia de perda de cientificidade nos estudos que não seguem os parâmetros do empirismo é preconceituosa. Porém, não estamos nos referindo à pesquisa empírica em si, pois nem toda pesquisa empírica é empirista. O termo empirismo se aplica, como já dissemos, 
aos pressupostos de que o que se necessita saber está no "puro" referente empírico (objeto). Em outras palavras, segundo González (2007, p. 50), para a perspectiva empirista, "a realidade é real e se captura através da experiência sensorial, que captamos como irritações nervosas de diversas intensidade e duração", sobre as quais são feitas as deduções e generalizações.

Pesquisas empíricas podem ser trilhadas a partir de diferentes metodologias e marcos conceituais. A visão fechada do empirismo não consegue reconhecer a possibilidade de haver distanciamento inteligente e rigor do pesquisador em processos de pesquisa, mesmo os métodos e técnicas sendo de natureza aberta. Existem pesquisas que não prometem neutralidade, mas geram conhecimento, pois o que interessa é desenvolver uma ciência que possa adentrar em domínios imperceptíveis às técnicas das ciências exatas, da saúde e biológicas. O que não quer dizer que se nega a necessidade e a importância das investigações quantitativas, experimentais e observacionais para determinados problemas de pesquisa. Cada problemática investigativa requer técnicas e procedimentos condizentes ao o que se quer saber. $O$ questionamento está na unidirecionalidade pretendida pela perspectiva hegemônica de pesquisa.

A ciência é histórica, se move, avança e se transforma em conformidade com o processo histórico das civilizações. Em momentos da história os fenômenos da natureza eram vistos como emanados de poderes transcendentais. Em outros momentos se tenta compreender os fenômenos na perspectiva apriorista, que privilegia o sujeito sobre o objeto. Ou seja, o importante não é o objeto, pois é a capacidade racional que leva ao conhecimento. "Se supõe que exista um número de categorias a priori, inatas mediante as quais conhecemos a realidade" (González, 2007, p. 49). Enfim, as posições epistêmicas passam pelo idealismo filosófico, que reconhece "o princípio espiritual como primeiro, e a matéria como aspecto secundário" (Triviños, 2012, p. 19), transitam no empirismo lógico, no materialismo dialético e no construtivismo, entre outras concepções. Empirismo lógico sedimenta o núcleo epistemológico no "dualismo radical" entre o "conhecimento empírico, extraído da experiência a partir da percepção direta de dados sensoriais, e a lógica, considerada linguagem que coordenaria e organizaria tal conhecimento se ajustando a regras formais da própria linguagem" (Garcia, 2002, p. 43). O materialismo dialético conjuga a filosofia materialista e a dinâmica da dialética na "tentativa de buscar explicações coerentes, lógicas e racionais para os fenômenos da natureza, da sociedade e do pensamento" (Triviños, 2012, p. 51). Está atento à história, às interconexões e ao movimento que transforma a realidade. Já para o construtivismo o conhecimento "não é relativo somente ao objeto e nem a razão, mas decorre da interação do sujeito e objeto, com destaque para o sujeito como produtor do conhecimento" (Siqueira \& Erdmann, 2007, p. 292). São posições epistemológicas que têm a ver com concepções de sociedade - por exemplo, as bases do materialismo dialético vêm da filosofia do marxismo que enxerga a sociedade como contraditória uma vez constituída a partir de classes sociais antagônicas -, que direcionam o olhar científico e os métodos a serem empregados.

Em última instância, toda pesquisa parte de uma posição epistemológica, ou seja, de uma concepção de mundo, mesmo que não seja consciente e/ou não explicitada por 
seus protagonistas. Desse modo, existem perguntas subjacentes a qualquer definição de problema de investigação. Pesquisar para que? Pesquisar o quê? Pesquisar como? E na área da Comunicação, como se vislumbrariam respostas a esse tipo de pergunta?

\section{Pela qualidade da pesquisa em Comunicação}

Não há dúvida de que a pesquisa em Comunicação pode ser tomada a partir de diferentes ângulos. Cada um deles pode levar a instigantes reflexões e conclusões, mas há um todo que desafia a investigação. Afinal o campo requer reflexões

articuladas em vários planos e níveis de análises: um ontológico, sobre a natureza da comunicação; (...) outro nível é o epistemológico, que questiona a comunicação como objeto de conhecimento, e evidentemente, a certos comunicantes (...) sujeitos desse conhecimento; e, por suposto um nível metodológico, que tem a ver com as maneiras em que esses objetos de conhecimento e de definição se formulam como objetos de investigação. Mas, antes do nível metodológico, creio que convém refletir sobre um nível praxeológico (...), pois a comunicação é, em sua essência geral, uma prática social ou, como corresponde dizer com mais precisão, uma prática sociocultural, sempre situada, contextualizada, historizada, cruzada pelo poder. (Fuentes Navarro, 2015, p. 12)

Nessa perspectiva se vislumbra a fertilidade objetual do campo que, com suas singularidades e ao mesmo tempo seus elos epistemológicos, transita numa transitoriedade incessante. Por um lado, trata-se de ciência recente, em processo de desenvolvimento rápido, mas, ao mesmo tempo, sofre diuturnamente as transformações tecnológicas e sociais das sociedades. Constitui-se em uma área desafiadora porque se revela muito ampla e dinâmica, com e sem fronteiras em relação a outras áreas do conhecimento. Ou seja, as configurações do universo praxeológico da Comunicação têm sido alteradas rapidamente nas últimas décadas - dos canais, aos meios e mensagens -, dos processos comunicacionais - interpessoais aos organizacionais, massivos, comunitários, digitais e online -, dos ambientes comunicacionais presenciais e midiáticos aos virtuais - e assim por diante, o que obriga a uma contínua busca pela revisão de conceitos e teorias, suas reelaborações e a formulação de novos conceitos e teorias para se dar conta das transformações. Por outro lado, a área congrega uma interdisciplinaridade interessante, ao perpassar e ser perpassada por outras ciências.

O que se pesquisa em Comunicação? Sem tentar responder esta pergunta, comentamos apenas, em primeiro lugar, que é grande a diversidade desde o ângulo do objeto explorado até às unidades de análise e os tipos de processos comunicacionais enfatizados. Essa diversidade é uma de suas riquezas e, talvez, de suas fraquezas. Simultaneamente à cobertura de temas e de objetos de pesquisa diversificados - até como reflexo da abrangência da área, como insinuado nos dois parágrafos anteriores -, o que complexifica o desenvolvimento de teorias, grosso modo, também corre-se o risco de 
dispersão, de pulverização de temas, de se dar ênfase às novidades, principalmente tecnológicas, e aos entornos dos processos comunicacionais. Parece haver resistência ou dificuldades em se partir da Comunicação, de formas, meios e de processos comunicacionais como foco. Do nosso ponto de vista, presta-se muita atenção a aspectos subjacentes, por exemplo, sociológicos, antropológicos, culturais, tecnológicos, narrativos, às vezes deixando em segundo plano a comunicação envolta no tipo de fenômeno analisado. Talvez seja reflexo dessa situação o fato de até hoje ainda se discutir no plano epistemológico o que é Comunicação, qual o seu objeto, e se ela se constitui ou não como ciência, disciplina e campo do saber. Como diz Melo (2011, p. 21), "ainda que não exista consenso, na academia, sobre a natureza do objeto das ciências da Comunicação, o fato é que, há meio século, vem se estruturando uma comunidade que pesquisa os fenômenos comunicacionais". Em meio à diversidade dos fenômenos estudados, no âmbito conceitual,

a multiplicação de propostas de reformulação teórica dos estudos de Comunicação manifesta uma insatisfação generalizada com o estado atual do campo e a urgência de repensar seus fundamentos e de reorientar o exercício prático. São análises convergentes, se bem que nem sempre complementares, análises que realizam revisões, redefinições, reestruturações, reinterpretações e rupturas com categorias analíticas, esquemas conceituais, métodos de investigação. Não obstante, são análises relevadoras da complexidade e da multidimensionalidade dos fenômenos comunicativos num mundo cada vez mais globalizado, multiculturalizado e tecnologizado, mas também cada vez mais fragmentado e desigual. (Lopes, 2003, pp. 282-283)

Em segundo lugar, a interdisciplinaridade característica dos processos de Comunicacionais, dos próprios fundamentos teóricos e das estruturas nas quais a instituições midiáticas se enraízam, ao mesmo tempo que a fortalece, torna difícil a delimitação dos objetos e a demarcação de fronteiras em relação a outras áreas do conhecimento.

Ao lado da diversidade temática há certa disparidade metodológica na pesquisa em Comunicação, especialmente no Brasil e em outros países da América Latina. Existem pesquisas metodologicamente consistentes no desenho dos métodos e técnicas, bem como nas análises dos observáveis e nas formas de apresentação das metodologias empregadas. Parece que os cursos de pós-graduação stricto sensu e grupos de pesquisa têm ajudado a promover avanços nesse sentido. Mas, há também pesquisas elementares, do ponto de vista metodológico, pelo menos, a julgar pelos trabalhos apresentados em congressos e publicados em revistas científicas, embora seja uma ocorrência também em dissertações e teses. Ao mesmo tempo há uma tendência em minimização descritiva das metodologias empregadas. A superficialidade na descrição e/ou a omissão das metodologias usadas são prejudiciais ao desenvolvimento científico da área. Talvez essa situação seja até um sintoma da tendência ao paperismo [paperism], como disse González (2017). A pressão acadêmica por difusão da produção científica, acentuada pela atual 
política de ciência e tecnologia, acaba por induzir mais a produção de papers (comunicações) e artigos ligeiros sobre temas emergentes e a abordagem de resultados parciais de pesquisa, do que a apresentação mais densa de análises de pesquisas concluídas.

Nesse contexto, predomina a tendência de elaboração e difusão de estudos de primeira ordem, presos a descrição de propriedades e elementos de um objeto. As entrevistas abertas semiestruturadas, análise de discursos, estudos documentais, além da pesquisa bibliográfica são técnicas amplamente utilizadas em pesquisas desse tipo, mas também são usados os questionários e análise de conteúdo como técnicas de investigação. Porém, afirmações mais aprofundadas sobre essas questões demandam investigações sistemáticas e de amplitude nacional.

Se há algo de interessante, entre outros aspectos, é a tendência observada, embora de modo assistemático e não exaustivo, a estudos empíricos - de cunho empirista ou não -, embora haja o desafio em se complexificar os recortes objetuais, as metodologias empregadas e as análises. Sinais de presença da preocupação com a qualidade da pesquisa em Comunicação são percebidos em palestras, grupos de trabalho de congressos da área, capítulos de livros, artigos, e teses defendidas em programas de pós-graduação, especialmente por meio da pesquisa da pesquisa desenvolvida por pesquisadores (Ferrara, 2003; Lopes, 2003; Maldonado, 2003; Melo, 2011; Sodré, 2014) atentos às teorias da Comunicação e às questões da epistemologia e das metodologias científicas.

Em suma, no que tange à questão metodológica, alguns desafios acercam-se da pesquisa em Comunicação. Urge aperfeiçoar os estudos de primeira ordem por intermédio do uso de metodologias mais complexas de modo a melhorar as descrições e, ao mesmo tempo, entender os fenômenos comunicacionais em suas complexidades. Simultaneamente é premente a passagem de estudos de primeira ordem aos de segunda, terceira e quarta ordens (Garcia, 2002; González, 2007) em nível de interpretação, o que requer o manuseio de abordagens mais aprofundadas. Enquanto abordagens de primeira ordem são descritivas das propriedades e elementos, as de segunda ordem são mais reflexivas e capazes de perceber as relações entre os observáveis e de cruzar teorias. Aquelas abordagens que miram os processos e desenvolvem um nível de interpretação ainda mais elevado, ao serem capazes de gerar conceitos são as de terceira ordem. As de quarta ordem são ainda mais avançadas pois desenvolvem teorias e partem da epistemologia para a interpretação, análise e explicação dos problemas teóricos e metodológicos.

A opção por determinada estratégia metodológica decorre da pergunta de pesquisa formulada inicialmente, que por sua vez sai do problema de investigação - formulado a partir de uma situação prática concreta e problematizada conceitualmente - que se quer compreender. Portanto, a delimitação do objeto (não confundir com unidade de observação) conduz a problemáticas mais ou menos relevantes. A relevância pode estar no grau de contribuição dos resultados para o desenvolvimento dos conceitos e teorias e no nível elevado de compreensão dos fenômenos complexos, além de sua importância - em saber teórico e/ou em sua aplicabilidade - para grupos sociais e para a sociedade como um todo, entre outros aspectos. 
Para arrematar essa parte, gostaríamos de acrescentar que pesquisas metodologicamente consistentes casam bem com temáticas relevantes. A junção de metodologia complexa com temática de alta relevância da pesquisa para a sociedade é um dos componentes importantes que justifica o investimento em pesquisa, seja o esforço pessoal ou as verbas públicas. Faltam pesquisas que pudessem analisar exaustivamente os temas, objetos e metodologias privilegiados pela pesquisa em Comunicação, cujos resultados possibilitassem avaliar o grau de importância da mesma para a área do conhecimento e para a sociedade. Fica mais uma sugestão de pesquisa.

\section{APRoXimaÇões E diferenÇAS ENTRE MÉTOdOS E TÉCNICAS DE PESQUiSA}

As definições de "como pesquisar", além de tangenciar as questões epistemológicas costumam esbarrar em dúvidas sobre os métodos e, mais precisamente, sobre as diferenças entre método e técnica, até porque estes termos se alojam na palavra metodologia. Portanto, metodologia engloba métodos e técnicas, mas a palavra método não é sinônimo de técnica e nem da expressão procedimentos metodológicos. Método, vem do grego, e se escreve meta-odós, o que significa caminho para ir além. Meta (ir além) e odós (caminho, via). Portanto, método quer dizer via ou caminho de uma investigação. Esse caminho inclui os pressupostos epistemológicos (nem sempre explícitos), o marco conceitual (teorização) e o marco metodológico (estratégias metódicas e técnicas). A pesquisa sobre como estes elementos são processados é desafiante para a compreensão da pesquisa em Comunicação, do ponto de vista epistemológico, pois indicaria o grau de fundamentação e de teorização, além do percurso da pesquisa tendo em vista de sua coerência interna e validação no campo.

Reportando a Bachelard, Lopes (2010, p. 28) esclarece que a epistemologia é tomada no plano do desenvolvimento histórico da ciência e no nível operatório,

como prática metodológica, entendendo que a reflexão epistemológica opera internamente à prática de pesquisa. Dito de outra maneira, os princípios de cientificidade operam internamente à prática de pesquisa, uma vez que a crítica epistemológica é que rege os critérios de validação interna do discurso científico (...). Esta perspectiva epistemológica deve necessariamente envolver critérios de validação externa, apoiados na crítica feita pela sociologia da ciência ou do conhecimento.

Garcia (2008, p. 71), usa a expressão “marco conceitual e metodológico" como "nome e sobrenome de uma mesma entidade, que encerra, ao mesmo tempo, uma posição epistemológica, uma certa concepção de 'realidade' (cosmovisão), e uma modalidade de investigação".

Partindo dessas procedentes noções e, para efeito didático, podemos adotar tanto a expressão "marco conceitual e metodológico" como "método científico", se preferirmos, mas concebendo-as como comportando três dimensões: a epistemológica, a teórico-conceitual e a metódica propriamente dita, interconectadas e inseparáveis, embora com performances específicas. 
A dimensão epistemológica (ou marco epistêmico) indica a posição na filosofia da ciência, a matriz epistêmica, ou o sistema de pensamento, da qual decorrem outras decisões sobre as opções conceituais e metodológicas. A posição epistemológica indica se a pesquisa se alinha ao apriorismo, empirismo, construtivismo ou ao materialismo dialético, ou em outros termos ao positivismo, à fenomenologia, ao estruturalismo, ao funcionalismo, ao materialismo histórico dialético ou ao construtivismo, e suas variações, além de orientar (não determinar) a fundamentação teórica e nortear o método e os procedimentos técnicos de pesquisa. A matriz epistemológica é eleita pelo pesquisador, e sempre vai existir, pois reflete uma visão, uma concepção de ciência e de mundo, mesmo que não seja uma escolha consciente e deliberada. Garcia (2002, p. 120) é enfático ao afirmar que o marco epistêmico "representa um sistema de pensamento, raramente explicitado, que permeia as concepções da época numa determinada cultura e condiciona o tipo de teorizações que surgem em diversos campos do conhecimento".

A dimensão teórico-conceitual, que tem como raiz o marco epistêmico - ou um sistema de pensamento -, orienta e modula a fundamentação teórica, ou seja, a teorização que embasa ou da qual parte a investigação. E, em estudos mais avançados, orienta a nova teorização elaborada. Porém, mesmo que o marco epistêmico conduza e condiciona o marco conceitual, este não determina o conteúdo da teorização que será específica em cada investigação. Como diz Garcia (2002, p.120), "num marco epistêmico cabem inúmeros marcos conceituais" dentro de uma disciplina.

A dimensão metódica (ou marco metodológico) se refere aos princípios e preceitos que embasam a metodologia (palavra que comporta método e técnica) que condiz e conduz às práticas de pesquisa desenvolvidas. Ou seja, o método congrega os antecedentes (concepção de mundo e de ciência), os fundamentos teórico-metodológicos que embasam a estratégia de pesquisa e as técnicas facilitadoras das práticas de pesquisa para a geração de dados, coleta de informações e os observáveis. Em outras palavras, a dimensão metódica, por um lado, pressupõe o embasamento a partir dos conceitos que orientam concepção metódica e, por um lado, incorpora os instrumentos de coleta de dados e de informações, como o questionário, a entrevista, o grupo focal, a observação direta etc.

A concepção metódica da pesquisa-ação, por exemplo, possui um conjunto de princípios e delineamentos conceituais que indicam o tipo e o rumo da inserção do/a pesquisador/a na situação investigada, ou seja, sinalizam a estratégia macro metodológica deste tipo de investigação, que por seu turno vai delinear a prática da pesquisa e o emprego de técnicas.

Nessa perspectiva, o marco metodológico (a metodologia), possui dois componentes, a estratégia metódica (o método) e a(s) técnica(s). Repetindo, método não é sinônimo de técnica, ele antecede a técnica e vai indicar, inclusive, qual é a técnica mais pertinente ao desenvolvimento determinada pesquisa. Em última instância, método e técnica se complementam, em geral caminham juntos e até se entrecruzam, porém, em esferas um tanto distintas. As técnicas são os instrumentos usados para a coleta de informações e dados, para o registro das observações e a identificação dos observáveis. 
Também é conveniente distinguir entre dados e observáveis. Segundo González (2007, p. 60), é comum, principalmente na prática de investigação empirista, chamar de "dados" ou "evidências" as "configurações de informação que se obtém dos objetos. Ao chamar de observáveis, não só mudamos o nome das coisas, mas interessa ressaltar o decisivo papel do Sujeito e suas próprias determinações na construção do que verá e julgará como seus objetos". Assim sendo, observável pressupõe o dado acrescido da interpretação sobre ele.

Em geral existe mais preocupação com as técnicas do que com os métodos e as questões epistemológicas nas teses e dissertações nos cursos de Pós-Graduação em Comunicação, particularmente no Brasil. Porém, como já dissemos, nem mesmo os procedimentos metodológicos são sempre bem descritos de modo a ajudar o leitor a entender o processo através do qual se chegou a determinados resultados e assim poder conferir validade interna e atestar ou não credibilidade à pesquisa.

A pesquisa será crível por tudo o que demonstrar em termos de seriedade do processo de pesquisa, abrangência e pertinência dos métodos e técnicas empregados, e qualidade dos resultados, conjugados com sua relevância temática e capacidade de teorização. A relevância será notada ainda pela capacidade de responder às necessidades de conhecimento da área, do país e do continente nos quais se assenta.

Não faz sentido pesquisar na intenção única de gerar comunicações para congressos e/ou artigos aceitáveis por periódicos estrangeiros - que costumam até induzir temas de interesse e modos de expressão -, apenas para subir a pontuação individual nos rankings acadêmicos. A pesquisa científica faz sentido quando é feita para gerar conhecimento capaz de contribuir com subsídios à sociedade para o equacionamento de suas questões cruciais, dos problemas à compreensão das configurações histórico-políticas, comunicacionais, econômicas, culturais, enfim de todas as áreas constitutivas dessa mesma sociedade. Como diz Paulo Freire (1981, p. 36), há um caráter político da atividade científica, e questiona: "a quem sirvo com minha ciência? Esta deve ser uma pergunta constante a ser feita por todos nós”.

\section{CONSIDERAÇÕES FINAIS}

Para finalizar, sem concluir, a temática deste texto, tão árida e ao mesmo tempo instigante, reforçamos a existência da necessidade do fortalecimento das pesquisas em Comunicação, tanto as teóricas quanto as empíricas. Junto à delimitação de problemas relevantes a profundidade dos marcos epistêmico ${ }^{6}$ e teórico, e a pertinência do marco metodológico são de suma importância, além de implicar em clareza do ponto de vista epistêmico e o emprego rigoroso de métodos científicos e procedimentos técnicos competentes e capazes de responder às perguntas relevantes formuladas.

Uma problemática de pesquisa relevante tende a gerar resultados relevantes, capazes de surpreender, pela novidade e pela profundidade dos "achados". Do nosso ponto

${ }^{6}$ Dada a complexidade da questão epistemológica, em geral, nem se cobra dos programas de Pós-graduação em Comunicação brasileiros a explicitação do marco epistêmico, o que seria desejável pelo menos para o grau de doutorado. 
de vista, a pesquisa em Comunicação no Brasil não tem surpreendido muito, apesar de haver exceções. As tendências anteriormente discutidas refletem as trilhas de uma ciência, por vezes tateante em seus recortes epistêmicos, objetos e ancoragem metódica, mas em crescente processo de qualificação construtiva. Desse modo, não de se trata de afirmar se o que é produzido é ou não ciência, mas de instigar novas pesquisas e mais meta pesquisa. Pesquisas que levem em consideração elementos da teoria do conhecimento e as dimensões ontológica e epistemológica da Comunicação, que atentem para os objetos comunicacionais e o cuidado com as metodologias científicas empregadas. Mas, ao mesmo tempo, pesquisas abertas a compreensão, respeito e valorização das diferentes noções de ciência e de métodos científicos.

\section{REFERÊNCIAS BIBLIOGRÁFICAS}

Brandão, C. R. (1999). A participação da pesquisa no trabalho popular. In C. R. Brandão (Ed.), Repensando a pesquisa participante (pp. 223-252). São Paulo: Brasiliense.

Calhoun, C. (2012). Comunicação como ciência social (e mais). Intercom - Revista Brasileira de Ciências da Comunicação, 35(1), 277-310. doi: 10.1590/rbcc.v35i1.1108

Fals Borda, O. (2013). La ciencia y el pueblo: nuevas reflexiones sobre la investigación acción (participativa). In N. A. Herrera Farfán \& L. López Gusman (Eds.), Compromiso y cambio social. Textos de Orlando Fals Borda-antologia (pp. 301-319). Buenos Aires: El Colectivo-Lanzas y Letras-Extensión Libros.

Fals Borda, O. (2013a) Romper el monopolio del conocimiento. In N. A. Herrera Farfán \& L. López Gusman (Eds.), Compromiso y cambio social. Textos de Orlando Fals Borda - antologia (pp. 253-263). Buenos Aires: El Colectivo Lanzas.

Feyerabend, P. (1977). Contra o método. Rio de Janeiro: Francisco Alves Editora.

Ferrara, L.(2003). Epistemologia da comunicação: além do sujeito e aquém do objeto. In M. I. V. Lopes (Ed.), Epistemologia da comunicação (pp. 55-67). São Paulo: Loyola.

Freire, P. (1981). Criando métodos de pesquisa alternativa: aprendendo a fazê-la melhor através da ação. In C. R. Brandão (Ed.), Pesquisa participante (pp. 34-41). São Paulo: Brasiliense.

Fuentes Navarro, R. (2015). Desafíos e responsabilidades de los estudios de la comunicación en América Latina. In M. A. Mattos \& M. E. Oliveira (Eds.), Desafios e perspectivas epistemológicas do campo comunicacional: estudos comparativos internacionais (pp. 10-23). Belo Horizonte: PUC-MG.

Fuentes Navarro, R. (2008). La comunicación desde una perspectiva sociocultural. Guadalajara: ITESO.

Galindo Cáceres, J. (Ed.). (2008). Comunicación, ciencia e historia. Madrid: McGraw-Hill.

Garcia, R. ( 2002). O conhecimento em construção. Porto Alegre: Artmed.

Garcia, R. (2008). Sistemas complexos. Conceptos, método y fundamentación epistemológica de la investigación interdisciplinária. Barcelona: Gedisa.

González, J. A. (2015). Por una cultura del conocimiento. In M. Maass, J. Amozurrutia \& J. Gonzalez, Cibercultur@e iniciación en la investigación interdisciplinaria (pp.303-380). Cidade do México: CNCA/ IMC/UNAM-CEICH. 
González, J. A. (2017). Entrevista. Tríade - Comunicação, Cultura e Mídia, 5(9), 246-253. Retirado de http:// periodicos.uniso.br/ojs/index.php/triade/article/view/3028/2690

Köche, J. C. (1997). Fundamentos de metodologia científica. Teoria da ciência e prática da pesquisa. Petrópolis: Vozes.

Lopes, M. I. V. (2003). Sobre o estatuto disciplinar do campo da comunicação. In M. I. V. Lopes (Ed.), Epistemologia da comunicação (pp. 277-293). São Paulo: Loyola.

Lopes, M. I. V. (2010). Reflexividade e relacionismo como questões epistemológicas na pesquisa empírica em comunicação. In J. L. Braga, M. I. V.Lopes \& L. C. Martino (Eds.), Pesquisa empírica em comunicação (pp. 29-49). São Paulo: Paulus/Compós

Maldonado, A. E. (2003). Explorações sobre a problemática epistemológica no campo das ciências da comunicação. In M. I. V. Lopes (Ed.), Epistemologia da comunicação (pp. 205-225). São Paulo: Loyola.

Martin Serrano, M. (2007). Teoría de la comunicación. La comunicación, la vida y la sociedad. Madrid: McGraw-Hill.

Martino, L. C. (2003). As epistemologias contemporâneas e o lugar da comunicação. In M. I. V. Lopes (Ed.), Epistemologia da comunicação (pp. 69-111). São Paulo: Loyola.

Melo, J. M. (2011). Memória do campo acadêmico da comunicação: estado da arte do conhecimento empírico de natureza historiográfica. In M. Barbosa \& O. J. Morais (Eds.), Quem tem medo de pesquisa empírica? (pp. 19-75). São Paulo: Intercom.

Minayo, M.C. S. (2011). O desafio da pesquisa social. In Minayo, M. C. S. (Ed.), Pesquisa social. Teoria, mpetodo e criatividade (pp. 9-29). Petrópolis: Vozes.

Morágas Spà, M. (2011). Interpretar la comunicación. Barcelona: InCom-UAB/Gedisa.

Peruzzo, C. M. K. (2016). A pesquisa participante, de uma matriz teórico-metodológica às especificidades das práticas investigativas. Comunicação apresentada no XIII Congreso da Asociación Latinoamericana de Investigadores de la Comunicación, Univ. Autônoma Metropolitana / Univ.Nacional Autonôma do México, Xochimilco/Cidade do México-México. Retirado de http://alaic.org/descargas/2016/GT8.pdf

Piaget, J. \& Garcia, R. (2011). Psicogênese e história das ciências. Petrópolis: Vozes.

Santos, B. de S. (1989). Introdução a uma ciência pós-moderna. Rio de Janeiro: Gral.

Siqueira, H. C. H de \& Erdmnn, A.L. (2007). Construtivismo como método de pesquisa: possibilidade de geração de conhecimentos. Revista de Enfermagem UERJ, 15(2), 291-297. Retirado de http://www.facenf. uerj.br/v15n2/v15n2a21.pdf

Sodré, M. (2014). A ciência do comum. Notas para o método comunicacional. Petrópolis: Vozes.

Thiollent, M. (1981). Investigación-acción. Chasqui, 1, 76-78. Retirado de http://chasqui.ciespal.org/index. php/chasqui/article/view/975

Thiollent, M. (2003). Metodologia da pesquisa-ação. São Paulo: Cortez.

Triviños, A. N. S. (2012). Introdução à pesquisa em ciências sociais. A pesquisa qualitativa em Educação: o positivismo, a fenomenologia, marxismo.São Paulo: Atlas. 


\section{NOTA BIOGRÁFICA}

Cicilia M. Krohling Peruzzo é Doutora em Ciências da Comunicação pela Universidade de São Paulo (ECA-USP). Fez pós-doutorado na Universidade Nacional Autônoma do México. Professora aposentada da Universidade Federal do Espírito Santo. Bolsista por produtividade do CNPq. Autora dos livros Relações públicas no modo de produção capitalista, Comunicação nos movimentos populares - a participação na construção na cidadania e Televisão comunitária - dimensão pública e participação cidadã na mídia local. Organizadora de algumas coletâneas. Possui artigos publicados em diversas revistas científicas nacionais e internacionais. Membro do Comitê de Assessoramento Artes e Comunicação do CNPq.

E-mail:kperuzzo@uol.com.br

Morada: Rua Dr. Nicolau de Souza Queiroz, 194 - ap.201, CEP 04105-000 São Paulo - SP, Brasil

* Submetido: 02.11.2017

* Aceite: 15.03 .2018 